\section{PROGERIA AND ATELEIOSIS. ${ }^{1}$}

By ARTHUR KEITH, LL.D., M.D. AbERD., F.R.C.S. ENG., CONSERVATOR OF THE MUSEUM AND HUNTERIAN PROFESSOR, ROYAL COLLEGE OF SURGEONS OF ENGLAND.

IN 1897 Mr. Hastings Gilford, of Reading, described a very remarkable condition or disease in a boy to which he gave in 1904 the name of progeria ( $\pi \rho{ }^{\prime} \gamma \eta p o s$, prematurely old). By his kind permission $I$ am enabled to reproduce here a photograph of his first case. (Fig. 1.) The photograph represents a boy of very peculiar appearance, 17 years of age (he died at the age of 18). His stature was only $1130 \mathrm{~mm}$. (3 ft. $8 \frac{1}{2}$ in.), the height of a normal boy of 7 ; his weight was only $16 \mathrm{~kg}$. ( $35 \cdot 2 \mathrm{lb}$.). So representative is this of other cases since recognised that the illustration is sufficient to guide any one to the recog:nition of the condition described as progeria. In coming to the conclusion that the boy shown in Fig. 1 represented an unrecognised pathological state, Mr. Gilford was assisted by a case described by Sir Jonathan Hutchinson $^{2}$ in 1886 under the descriptive title of * Congenital absence of hair and mammary glands, with atrophic condition of the skin and its appendages in a boy whose mother had been almost bald from alopecia areata from the age of six." So like was the second boy to the first that when the father of Sir Jonathan Hutchinson's case saw the photograph of Mr. Gilford's case he believed he was looking at a photograph of his own son. In 1910 two French physicians, M. Variot and M. Pironneau, described a third case of a girl-absolutely identical with the English caseunder the title of "Le Nanisme Type Sénile (Progeria de Gilford)." 4

Progeria, ${ }^{5}$ as defined by Mr. Gilford, does not occur in normal children; it only affects those who are the subjects of a form of delayed or arrested growthinfantilism. Progeria is thus a double condition: (1) the body is .arrested or delayed in its growth; and (2) it becomes prematurely the subject of senile changes. Infantilism and senilism are both present in the same body at the same time. Progerians pass from a delayed childhood into a premature old age. Mr. Gilford, in his recent work, cites a case which illustrates the acceleration of age changes to a remarkable degrese. In eight months a

1 Demonstration at the Rojal College of Surgeons of England on

Oct 18th, 1912 .
2 The clinical features of the disease and an explanation of its nature are given in Mr. Gilford's stexling work, "The Disorders of Post-Natal Growth and Development." Arlard, 1911.

3 Merlico-Chirurgical Transactions, 1826, rol. 1xix.. p. 474

5 In the Zeitschrift fur Ethnologie, 1912, vol xil p. 705 . 592 a peculiar 5 In the Zeitschrift fuir Ethnologie, 1912, vol. xliv, p. 592, a peculiar ancient Peruvian skull is described by Professor von Luschan and Dr described here as progeria.
St. Louis baby had reached that stage of development of the head and face usually attained by men between 40 and 50 years of age ; in this case the individual appears to have passed in the short space of eight months to an imperfect state of manhood.

I have two reasons for calling attention to progeria. The first is to see if it is so rare a condition as is supposed ; it is not unlikely, when men in active practice become acquainted with the very definite characters of the disorder, that further cases will be recognised and additional light thrown on the exact nature of what is clearly an instructive disease. My chief reason, however, is to describe the changes in the skeleton of a lad who died at the age of 18 and was recognised as manifesting the typical features of progeria. The skeleton has been added recently to the Museum of the Royal College of Surgeons, and affords us an opportunity of
FIG. 1.

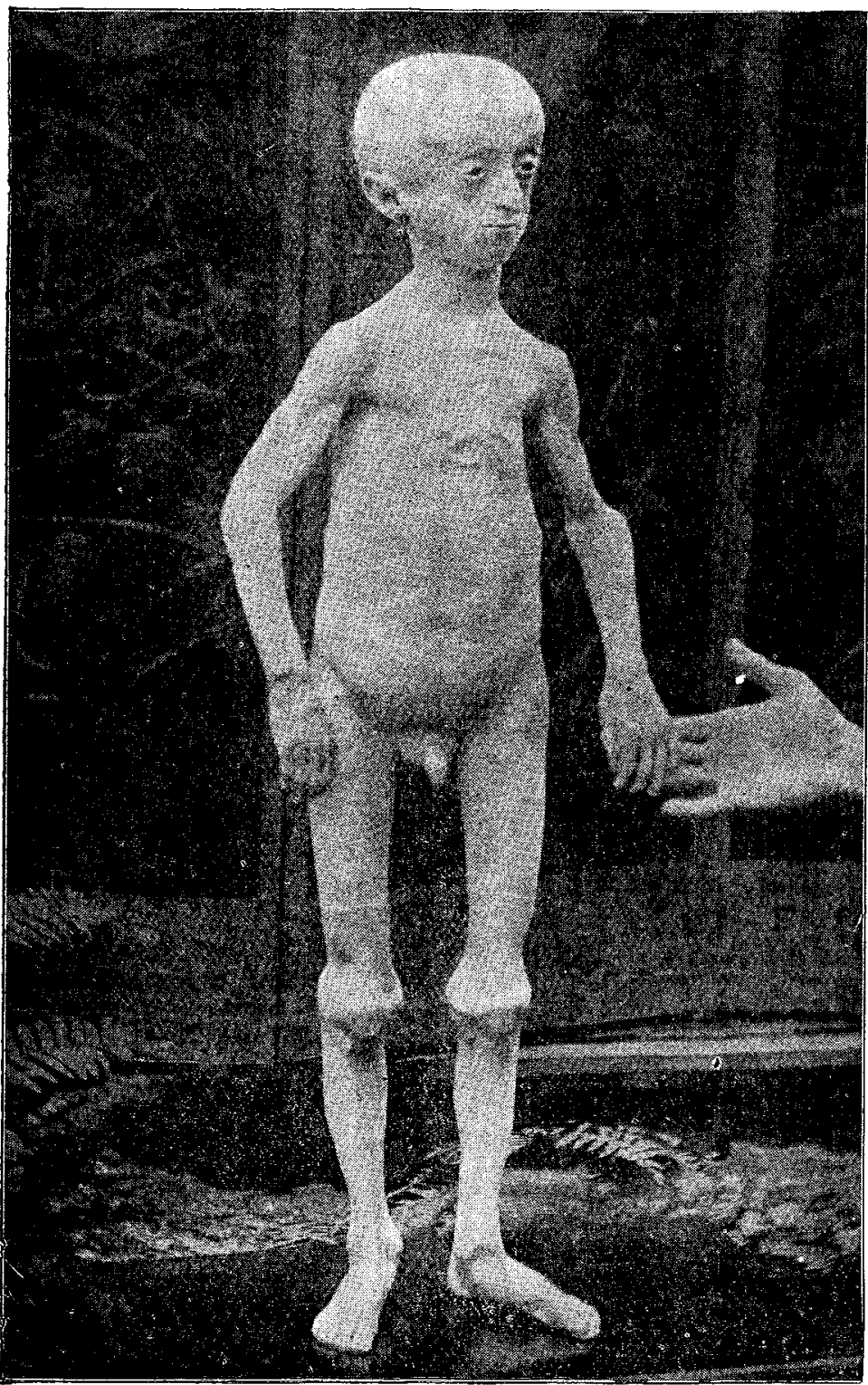
in stature, hair grey, skin wrinkled, stooping posture, ancl characteristic appearance (from ".
Mr. Gilford's case of progeria. A boy aged 17, 3 feet $8 \frac{1}{2}$ inches becoming acquainted with the peculiar and characteristic skeletal changes to be seen in cases of progeria.

Characters of the skull.It will be unnecessary to describe these at length because Figs. 2, 3, and 4 give accurate representations of both the internal and external characters of the skull, as seen in side view, front view, and top view. The plane of orientation and the exact scale are shown on the figures so that any measurement desired may be obtained from them. The condition of the sutures and fontanelles is also shown. A glance at Figs. 2 and 3 will show at once that while the brain-case is nearly of normal size the facial part of the skull has been arrested in its development and growth ; it is infantile in its dimensions. The outstanding features of the head are those which depend on arrested or delayed growth, but an arrest which is more profound than is known to occur in any other disease.

Cranial cavity and brain case.-The skull, from a functional point of riew, falls into three parts: (1) the cranial walls moulded on the brain and designed to protect the brain; (2) the facial parts and apparatus of mastication; and (3) the parts modified for the fixation of the skull to the body. That is the order in which I propose to describe the various cranial changes which are to be seen in progeria. In the present case there was a peculiar attitude of mind, but the patient was not mentally deficient. The cranial capacity is in keeping with the obserration made in life; it measures 1250 c.c., which, although over 200 c.c. below the average capacity of English lacls of 18, is yet as large as in many boys of good mental capacity. The maximum length of the skull is $166 \mathrm{~mm}$. The bones of the skull are so thin that the actual length of the cranial cavity is $162.5 \mathrm{~mm}$., the thickness of the frontal and occipital walls having only a combined measurement of $3.5 \mathrm{~mm}$. about one-fourth of the normal amount. The total length is less than we should expect-a result, as we shall see, of the delayed growth of the base and facial 
part of the skull. The brain, however, has apparently gained the necessary space by expanding laterally (see Fig. 3), and hence the skull is wide, its width being $84 \cdot 3$ per cent. of the length. The maximum width is $140 \mathrm{~mm}$., the thickness of the lateral cranial wall on each side being only $2 \mathrm{~mm}$. The shape of the cranial case has also been affected by a premature obliteration of the lambdoid suture (see Fig. 2), and of the suture between the frontal and great wing of the sphenoid. The suture between the great wing and the malar is also synostosed. One effect of the delayed growth of the cranio-facial base and of the premature closure of these sutures is that the brain has expanded the posterior part of the skull, especially where the parietal, occipital, and mastoid regions meet. In that region there is a large font anelle bounded by thin and exceedingly delicate bone. The external auditory meatus has, owing to the posterior expansion of the skull, come to be situated in front of the mid-point of the antero-posterior axis of the head. The height of the vault of the skull above the ear holes is only $110 \mathrm{~mm}$., about $15 \mathrm{~mm}$. less than is to be expected in a normal head. The lowness of the vault is due (1) to the relatively small cranial capacity ; (2) the thinness of the parietal bones at the vault $(1.5 \mathrm{~mm}$.); and (3) to the complete arrest in the downward and outward growth of the auditory meatus; the region of the mastoid (see Fig. 2) has proceeded very little beyond the stage reached at birth. In progeria the brain, although distinctly below the average size, is not small, but the cranial walls are exceedingly thin, and there is some irregularity in shape owing to premature synostosis of certain sutures. In life there was a considerable degree of asymmetry observed when the head was viewed from above; the normal prominence of the left occipital was exaggerated. The skull shows still a considerable asymmetry from above (Fig. 4), but to a less degree than was observed in life.

Facial and masticatory part of the skull.-It is very apparent from Figs. 2 and 3 that there has been a profound arrest of growth of the face and of all those parts which are concerned in mastication. By the eighteenth year the face should be rapidly attaining its mature size; the deficiency in the present case is shown in Fig. 5, where a profile of a typical English skull is contrasted with. progeria on the one hand and with acromegaly on the other. In the one case (progeria) there is an arrest of growth in the facial parts; in acromegaly there is an overgrowth; yet the difference in age between the patients suffering from these two extreme conditions was only four years. The total length of the progerian face from nasion to chin is only $84 \mathrm{~mm}$. (normal 110-120 mm.); the length of the upper face-from nasion to the alveolar point $-45 \mathrm{~mm}$, about $15-20 \mathrm{~mm}$. too small. The width of the face-from one zygomatic arch to the other-is only $92 \mathrm{~mm}$. in place of $110-120 \mathrm{~mm}$.; the width between the masseteric tubercles of the malars is only $54 \mathrm{~mm} ., 20 \mathrm{~mm}$. less than is usual. Those measurements illustrate the marked arrest of growth in the face. The condition of the air sinuses is even more significant. The maxillary sinus is no larger than at birth; the roots of the molar teeth appear in the floor of the orbit. The frontal, ethmoidal and sphenoidal sinuses, which ought at the eighteenth year to have attained very considerable dimensions, are still unformed.

Palate and upper teeth.-The condition of the palate, a very remarkable one, is shown in Fig. 6. There is a profound arrest of growth; the permanent teeth are struggling to find room on a palate which is very little larger than the palate of a child at birth. The palatal area bounded by the teeth is narrow and vaulted. At the age of 18 the palatal space (within the teeth) should have an area of $950 \mathrm{~mm} .{ }^{2}$; in progeria it is only $410 \mathrm{~mm} .^{2}$ Between the first premolars it forms merely a groove $5.5 \mathrm{~mm}$. wide; in a normal boy the width should be about $30 \mathrm{~mm}$. In its length the palate is less reduced than in its width. The length measured from the alveolar border, between the central incisors, to the mid-point of a line uniting the posterior borders of the second molar teeth, measures $33.5 \mathrm{~mm}$. -about $8 \mathrm{~mm}$. less than normal. The nasopalatine foramina are open, and the bones of the palate are thin and fragile. The dimensions of the palate and teeth are accurately shown in Fig. 6.

Although the growth of the palate is so delayed, the teeth, irregular in position and distorted, are quite as advanced in formation and eruption as we expect to find in a youth of 18. The upper central incisors, peculiarly bent (see Fig. 2), are in place ; their roots are very short, and the crown of the left is almost destroyed by caries. The first and second premolars have erupted. The first have appeared on the lingual sides of the persistent first milk molars; the second permanent premolars have come through behind their normal position and have rotated, so that the anterior interdental surface of the crown is turned towards the tongue. The first and second permanent molars are struggling into place, but the process of eruption has been so irregular that the grinding surface of the first molar abuts against the anterior side of the crown of the second molar. (Fig. 6.) The crowns of these two molars are firmly fixed together, and scarcely rise above the level of the alveolar border. The pressure of the first molar has caused the roots of the second molar to become sharply bent at their junction with the crown. The third permanent molars have not been formed; no trace of these teeth could be seen. Apparently the upper lateral incisors were never formed; their place is taken by persistent lateral milk incisors. Still embedded in the alveolus and lying inside the lateral milk incisors are the crowns of the permanent canine teeth. They lie obliquely, their points directed forwards. Thus while the palate is no larger than that of a child of two years, the teeth, in point of formation, and also eruption, are not markedly behindhand. The absence of the lateral incisors and wisdom teeth shows that there has been an arrest in dental development, but the chief of the dental irregularities must be attributed to the disturbed growth of the palate and upper jaws.

Mandible and lower teeth.-In Fig. 7 is given an exact drawing of the mandible and teeth-viewed from above, in natural size; the mandible is represented in true profile in Fig. 2, one half natural size. It will be seen that although in dimensions the mandible exceeds that of the newly born child, yet it has retained the infantile configuration to a remarkable degree. At first sight one is inclined to explain all its characters as the result of an arrest of growth. The ascending ramus is not developed; the coronoid processes are flush with the alveolar border, and the condyles lie in line with the lower border of the body of the mandible (see Fig. 2). The symphysis has larger dimensions than at birth its height measures $16.5 \mathrm{~mm}$. - its thickness, from front to back, $10 \mathrm{~mm}$. The width from the outer border of one condyle to the outer border of the other is $78 \mathrm{~mm}$.-much greater than at birth. There is a certain degree of asymmetry (see Fig. 7), the right condylar and coronoid processes being less developed than on the left side. The condyles, as may be seen from Fig. 7, are remarkably small. In life the patient found difficulty in opening the mouth, the range of mandibular movements being limited. The lingual or intraalveolar area of the palate, we have seen, was very small but the corresponding area between the lower teeth is not reduced to a corresponding extent. The non-development of the ascending ramus of the mandible is eorrelated with the non-expansion of the maxillary antrum and arrest in vertical growth of the upper jaws. The mandible, as may be seen from Fig. 2, occupies an oblique position on the face, passing in a straight line from a feebly developed chin towards an equally reduced auditory meatus. In shape the mandible represents a condition of infantilism, and yet there are certain features present which are not to be seen in the jaw at birth.

The condition of the lower teeth is represented in Fig. 7. The milk teeth on the right side have been destroyed by caries, with the exception of the first molar. The first permanent molars have also been destroyed by caries. The central permanent incisors are in place, sloping backwards, as shown in Fig. 7, owing to the oblique manner in which the mandible is set as regards the face. On each side of the central incisors are two teeth which are apparently the permanent canines (Fig. 7), the lateral incisors being congenitally absent, as is also the case in the upper jaw. Outside the canines and imbedded within the jaw in an oblique position are the permanent first premolar teeth much further back (see Fig. 7) are the unerupted crowns of the second premolars. The first permanent molars have been destroyed by caries, after coming into use. The second permanent molars are erupting from the inner aspect of the coronoid processes-the grinding surfaces of the crowns looking inwards. The roots of these teeth (see Fig. 7) are formed, although the crowns lie in the alveolus. There is no trace of formation of third molars. Thus, although the mandible is infantile in form the teeth have reached a 
stage in eruption corresponding to about the eighteenth year.

Other parts of the masticatory system.The undeveloped condition of the face, palate, and mandible has been mentioned, but there still remain certain other parts of the masticatory system which require description. The zygomatic arches (Fig. 2) form slender bars of bone, only $2 \cdot 5 \mathrm{~mm}$. in depth, and so fragile that one must infer an equally undeveloped condition for the masseter muscle. The temporomandibular joint retains the infantile form. There is no articular eminence, no glenoid cavity, merely a flat articular surface. The condyle of the mandible is little larger than at birth. The tympanic plate which is developed to complete the temporomaxillary joint behind-it is a part of the structures concerned in mastication-also retains the ring form seen in infancy. The temporal muscles were also exceedingly feebly developed. The extent of their attachment is indicated by the temporal lines; as the muscles grow and expand on the sides of the skull, the temporal lines ascend at the growing border of the muscles. By the eighteenth year the temporal lines should have ascended to a point about $75 \mathrm{~mm}$. above the upper margin of the posterior part of the zygoma; in the case of progeria the temporal lines lie only $55 \mathrm{~mm}$. above the root of the zygoma.

With the eruption of the permanent teeth, the growth of the jaws, and of the muscles of mastication, certain wellknown changes occur on the forehead which strengthen the bony scaffolding of the face. The frontal sinuses enter and

FIG. 3.

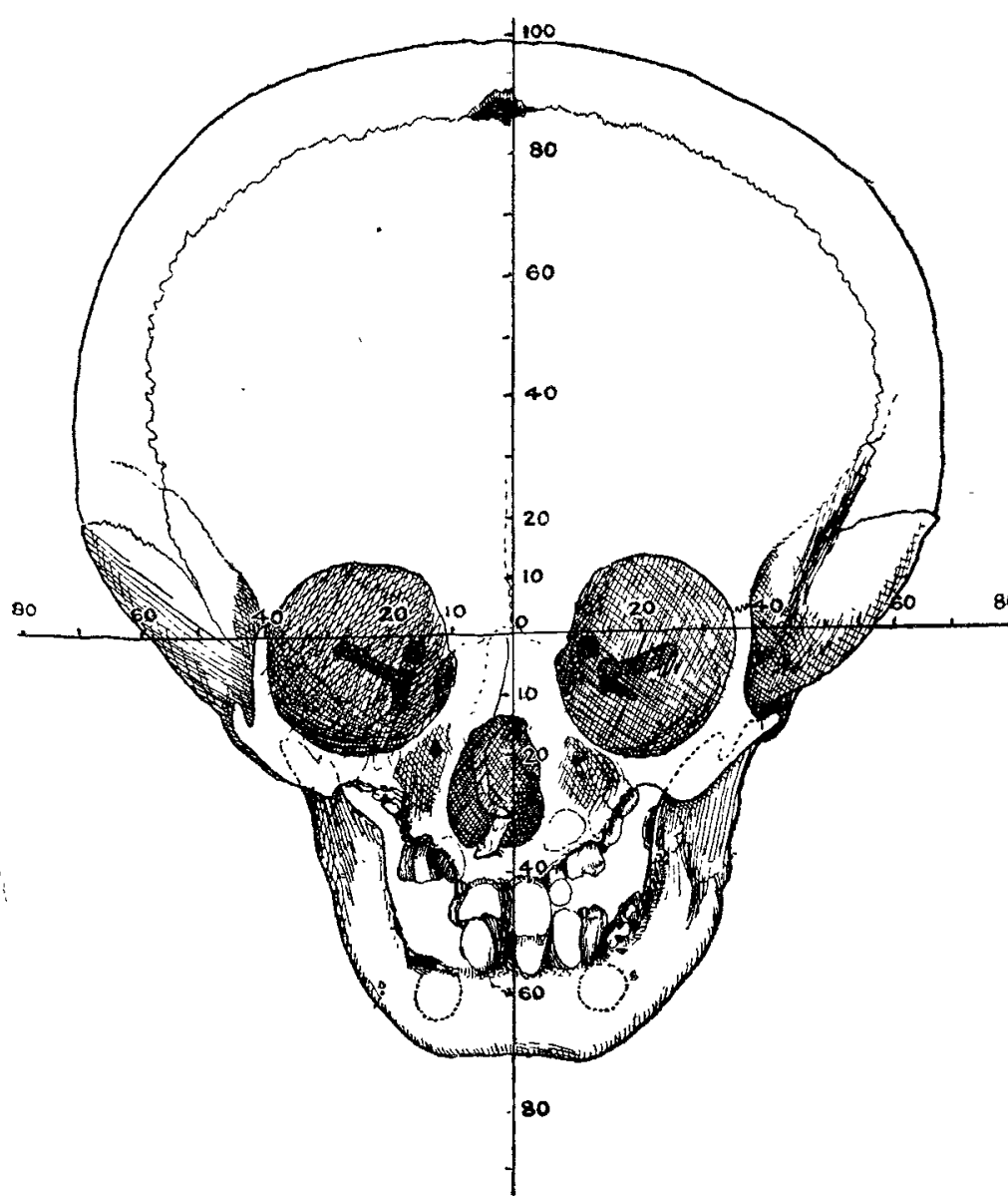

The skull of progeria seen from the front. The lateral expansion of the cerebral part, the arrest of growth of the facial and of the mastoid regions is apparent.

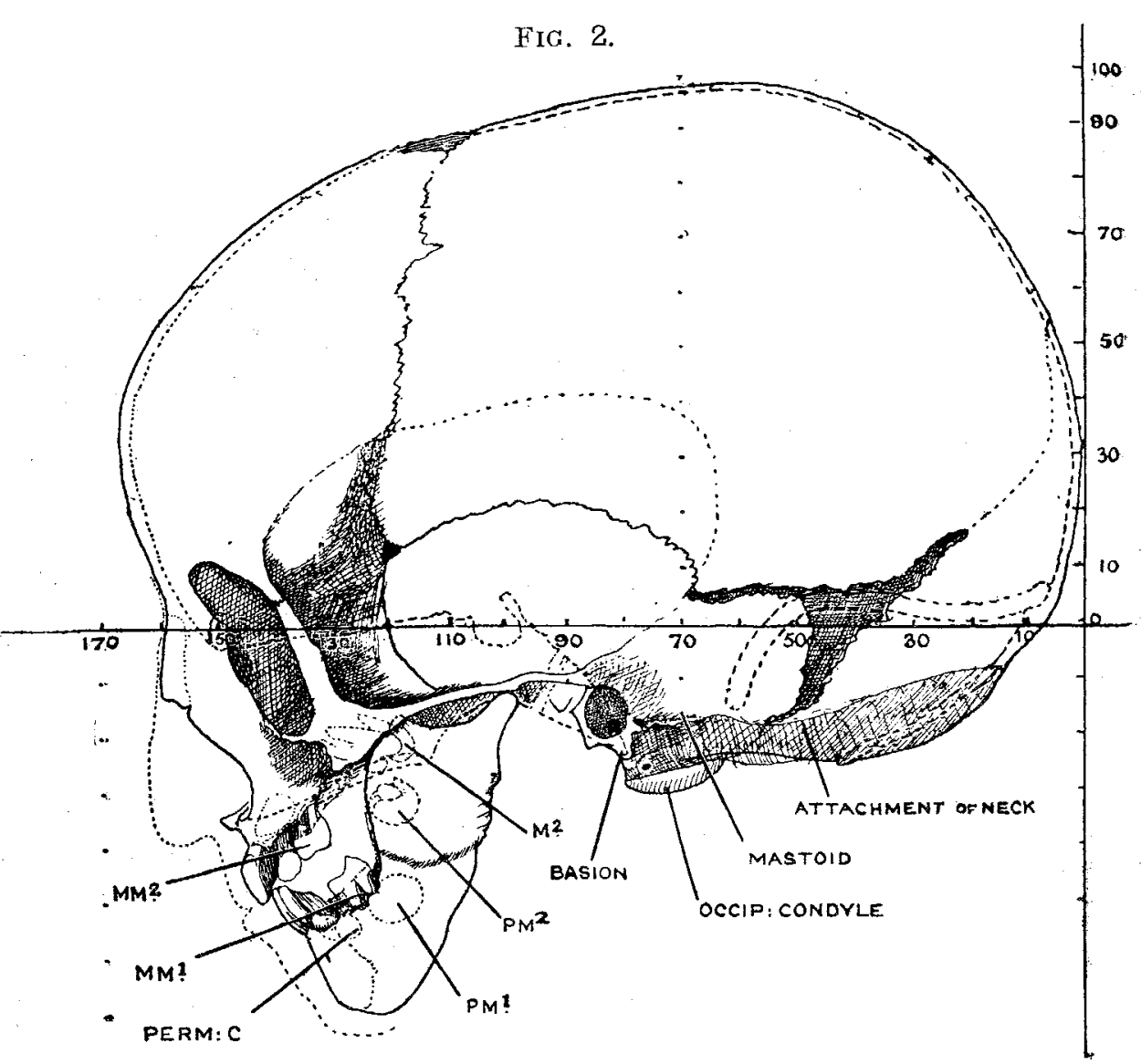

Profile of skull. The interior of the skull, with pituitary fossa, is represented by a stippled line. $M_{-} M^{1}, M_{M} M^{2}$, first and second milk molars. $P M^{1}, P M^{2}$, first and second premolars. Perm. C, Permanent canine. ${ }^{2}{ }^{2}$, Second permanent molar behind the first permanent molar. The obliterated sutures are also represented by stippled lines.

inflate the supranasal region of the frontal; the supraciliary eminences appear ; the supra-orbital ridges and external angular processes are formed. In progeria the development of all these features is arrested. The most projecting part of the forehead is above in the region of the frontal eminences; the lower part of the forehead is retracted, smooth, finely moulded, and retains the characters of infancy. The width of the forehead from one temporal line to another is $86 \mathrm{~mm}$, about $8 \mathrm{~mm}$. less than we expect to find in crania of normal youths. In a normal lad of 18 the width of the forehead, from one external angular process to another of the frontal, should be $95-100 \mathrm{~mm}$. ; here it measures only $77.5 \mathrm{~mm}$. Thus all the parts of the skull concerned in mastication are markedly arrested in growth. The walls of the alimentary canal were observed to be thin and atrophied when an examination was made immediately after death.

Fixation of the skull to the neck. - It is well known that the occipital region of the skull undergoes a so number of changes in form and size during the years of adolescence. The neck grows when the brain has ceased to expand; the head becomes more deeply set in the neck as youth passes into manhood. In progeria none of these changes occur; the occipital region of the skull retains all its infantile features. The mastoid processes are entirely undeveloped; they are represented by mere rough lines on the outer borders of the digastric fossæ. The occipital curved lines and inion are equally infantile in type. The bimastoid diameter-which represents the width of the neckis only $87 \mathrm{~mm}$. in extent-fully $20 \mathrm{~mm}$. less then is to be expected. The external auditory meatus is also infantile in form. The occipital condyles are small and flat; they measure $18 \times 8 \mathrm{~mm}$. The foramen magnum is spacious, measuring $36 \mathrm{~mm}$. (antero-posterior) by $32 \mathrm{~mm}$. (width). The large size of the foramen magnum is due to the persistence of the occipital fontanelle at its posterior margin. The large foramen is really an infantile character. Associated with the unfilled condition of the occipital fontanelle is the partial absence of the posterior arch of the atlas. 
Pituitary fossa. - The pituitary fossa is peculiar-in shape and smaller than is usual. The dorsum sellæe and posterior clinoid processes are so developed that they overhang the pituitary fossa, almost reaching the anterior clinoid processes and leaving a passage, only $5 \mathrm{~mm}$. in its antero-posterior diameter, for the transmission of the infundibulum of the pituitary. The antero-posterior diameter of the pituitary fossa itself is $9 \mathrm{~mm}$., its width $14 \mathrm{~mm}$., its depth, measured from the level of the upper edge of the dorsum sellæ, $6.5 \mathrm{~mm}$. All of these measurements are below the normal, and yet not so much that one can say definitely that the pituitary was pathologically small in this case of progeria. We have seen how markedly the face had been arrested in its growth; the cranial axis, on which the face is implanted, is also arrested in its growth, and it might be suspected that the slight reduction in the size of the pituitary fossa is due to the general arrest of the cranial base. In achondroplasia the cranial base is arrested in its growth and the pituitary fossa is small. I do not think that a reduction in the size of the pituitary can be explained in this manner. We have seen that the brain obtained by its growth the expansion of skull required for its accommodation. In cases of acromegaly we see pituitary tumours expanding the pituitary fossa to a large size; we have no reason to think that in progeria and achondroplasia the growing pituitary would fail to obtain such space as it required. The mere fact that bony processes became developed in the roof

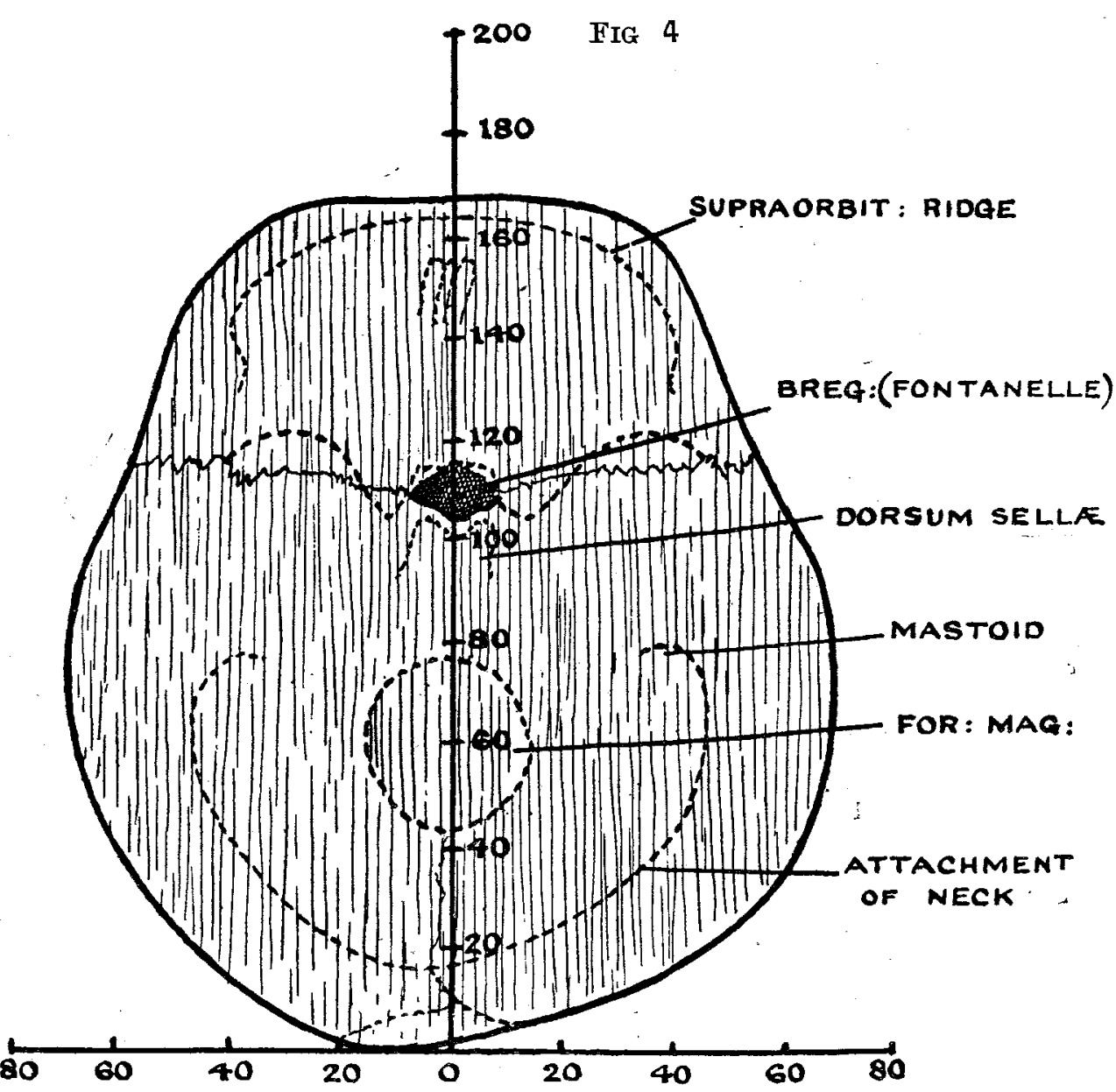

View of the skull from above (half natural size). The attachment of the neck, the foramen magnum, the pituitary fossa, and supraorbital ridges are also indicated.

of the pituitary fossa seems to show that there was no energy of growth in the pituitary, no tendency to expansion.

Infantile and senile characters of the skull.-A survey of the various peculiar features of the skull shows that nearly all of them may be regarded as indicating a persistence of an infantile condition. That is especially true of all the

FIG. 5.

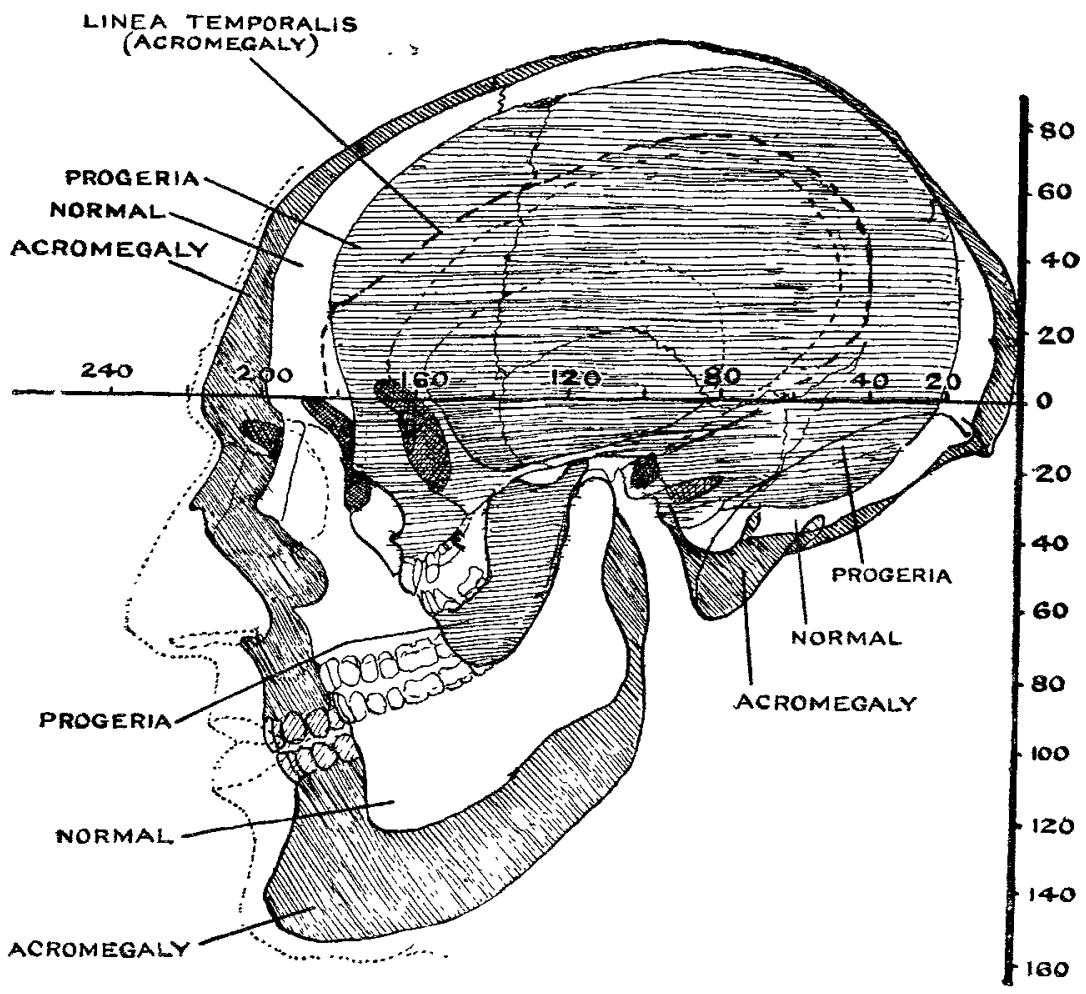

Superimposed protile drawings of three skulls: (1) progeria, (2) normal Finglish male; (3) O'Brian (ac-romegalic giant aged 22). It is apparent from this figure that progeria and acromegaly represent opposite conditions (3/10ths natural size). features of the forehead, face, and jaws, of the temporal, mastoid, and occipital regions. The thinness of the cranial walls $(0.5-2 \mathrm{~mm}$. thick), the almost complete absence of diploë in their structure, the persistence of a fontanelle at the bregma ( $20 \mathrm{~mm}$. wide by $15 \mathrm{~mm}$. from back to front), the large fontanelle at the asterion - a fœtal charactermeasuring $60 \mathrm{~mm}$. in its irregular length by $10 \mathrm{~mm}$. in width (see Fig. 2), and the persistence of the suture between the basi-occipital and basi-sphenoid bones, are all fotal or infantile characters. On the other hand, the cranial cavity, although below the normal capacity, cannot be regarded as arrested in its growth-at least not to a pathological extent. Thus, while the great majority of the cranial features may be regarded as infantile in nature, there are a number which cannot be regarded in this sense. The closure of sutures between adjacent bones is usually regarded as a senile character. The cranial sutural lines represent lines of growth-at least of potential growth; their closure in youth is certainly pathological, if not senile, in nature. In progeria the following sutures are closed: the greater part of the lambdoid (see Fig. 2); the sagittal (see Fig. 4); spheno-frontal ; spheno-malar ; temporo-malar. The coronal and temporo-parietal and temporo-occipital sutures were freely open and infantile in character. The other sutures prematurely closed are (see Figs. 2 and 3 ): fronto-maxillary; naso-maxillary; nasofrontal ; fronto-lacrymal; fronto-ethmoid; malomaxillary; and two already mentioned, sphenomalar and temporo-malar. The parts of the occipital bone were united and the synchondrosis between the basilar plates of the occipital and sphenoid bones remained open. The outer surface of the tabular bones of the skull show shallow dimplings and elevations, due to irregular deposit or growth on their outer tables.

The asymmetry of the mandible has been mentioned; there was also asymmetry of the nose (see Fig. 3). The nasal bones are relatively large and diverge to the right; the vertical plate of the ethmoid projects prominently from the nasal 
aperture and is bent with its convexity towards the right. The intranasal parts-turbinate processes-are small but normally developed. The height of the nose is $36 \mathrm{~mm}$.; the width of the aperture $16.5 \mathrm{~mm}$. The orbits, in conformity with the face, are high compared with their width. Their height is $35 \mathrm{~mm}$., width $31 \mathrm{~mm}$.

If one sums up the features of the skull the great majority must be regarded as a result of an arrest of growth, but there remain a small number which seem to indicate senility, at least prematurity.

Bodily proportions.-So far only the skull has been described; it is now proposed to give an account of the skeleton. In certain forms of dwarfism such as achondroplasia, some parts of the body and limbs are much more reduced than others; in acromegaly some bones or parts of bones are affected more than others. In progeria all the parts connected with the thorax and with respiration are reduced; in acromegaly the same parts The length of the clavicle is correlated with the width the normal is shown in Fig. 9. The standing height of and strength of the chest-the greater the development the progerian right femur is 298 mm. ; in the normal lad of the chest the longer the clavicle. In the case of it is $416 \mathrm{~mm}$, the first being thus $71.8 \mathrm{per}$ cent. of the

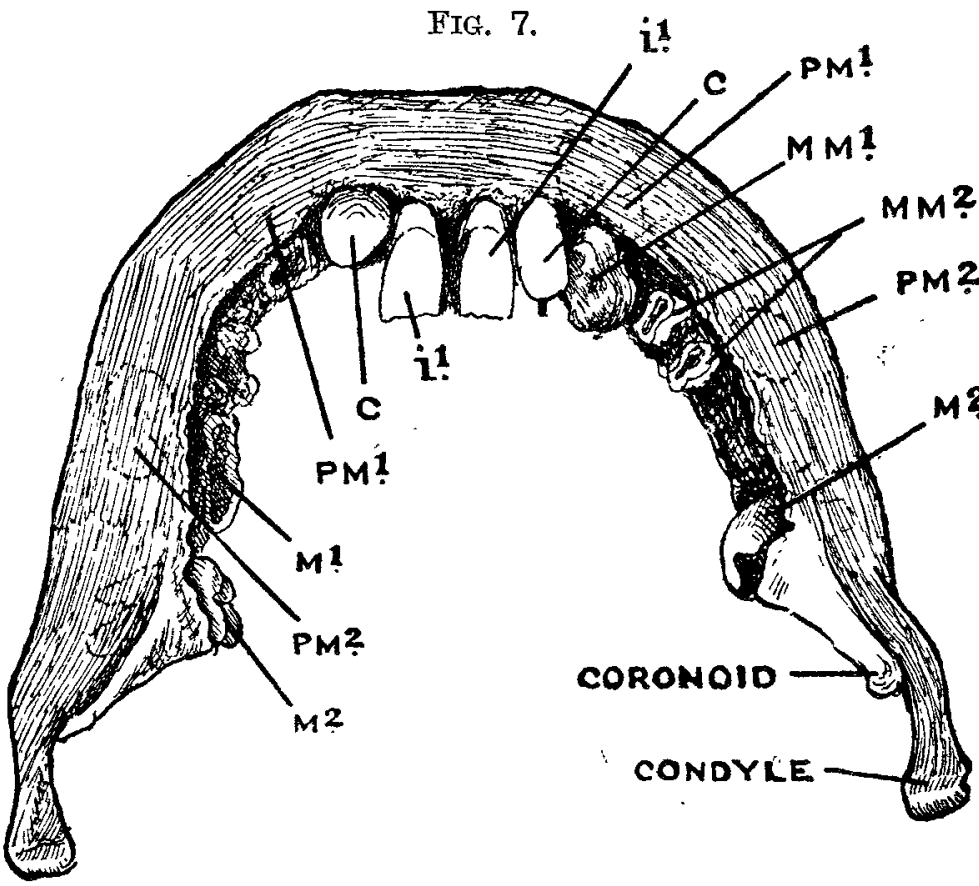

The mandible seen from above (viewed at right angles to tiłe alveolar border and drawn natural size).

progeria the length of the clavicle was measured during the post-mortem examination and found to be $55 \mathrm{~mm}$.; the length of the clavicle in a lad of 18 (R. C. S., No. 28.1) is $126 \mathrm{~mm}$; the clavicle in this case of progeria is 43.6 per cent. of the normal length (see Fig. 8). Comparing the seventh pair of ribs - of the skeleton of the normal boy of 18 with that of progeria-each rib, measured along its curvature, is $275 \mathrm{~mm}$. in the normal and only $150 \mathrm{~mm}$. in progeria; in length the latter is only 54.5 per cent. of the normal. The upper ribs are even reduced to a greater extent. In progeria intracartilaginous ossification is not disturbed to the same extent as intramembranous ossification, yet both are affected. As will be seen from Fig. 8, the cartilage-formed part of the clavicle is very distinctly demarcated from the membrane-formed portion. We should expect the membrane-formed clavicle to be more affected than the

\section{FIG. 6.} normal. The femur is thus less affected than the clavicle or ribs. The length of the tibia in the normal lad is $332 \mathrm{~mm}$., in the abnormal 230, being thus 81 per cent. of the normal and less affected than the femur. The os calcis-a purely intracartilaginousformed bone-had a total length in the normal of $69 \mathrm{~mm}$., in the abnormal $55 \mathrm{~mm}$, being 80 per cent. of the normal. The first metatarsal is peculiarly short. in the case of progeria; its length is $37 \mathrm{~mm}$.; the normal $59 \mathrm{~mm}$.; it is thus 62.7 per cent. of the normal. The upper epiphyses of both humeri are unfortunately missing, but the length may be estimated at $178 \mathrm{~mm}$., the normal $305 \mathrm{~mm}$., the first being 58.3 per cent. of the normal. The lower epiphyses. of the radius are missing, but the radial length was probably $134 \mathrm{~mm}$.; in the normal it is $230 \mathrm{~mm}$.; the progerian radius is thus 58.2 per cent. of the normal. Thus it will be seen that the bones of the upper extremity have suffered more than those of the lower. An exact comparison of the normal and abnormal scapulæe is shown in Fig. 10. The axillary border of the progerian bone is only 58 per cent. of the normal, the scapula being like the clavicle markedly reduced, although formed in cartilage. The total length of the os innominatum from iliac crest to. ischial tuberosity is 195 in the normal and 127 in the abnormal, equal to 65 per cent. of the normal. The various parts are reduced in equal ratio, except the ischium, which is particularly small. Taking the sacrum as representative of the axial skeleton it is seen to. be less reduced than the limb bones. Its total height, measured in a straight line from base to apex-its deoree of curvature is that usually found-is $72 \mathrm{~mm}$.; in the normal

FIG. 8.

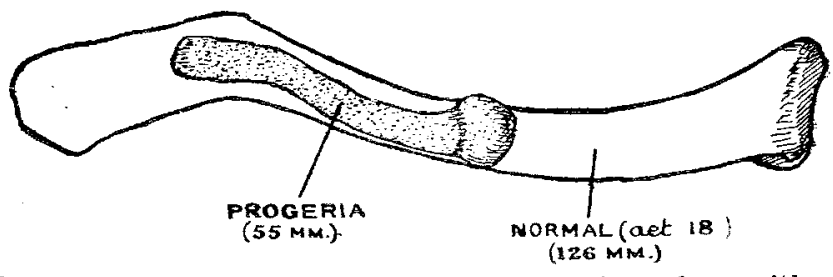

Right clavicle of a normal lad of 18 years seen from above with the clavicle of a case of progeria superimposed. (Half natural size.) 
$93 \mathrm{~mm}$. ; the sacral width in progeria is $74 \mathrm{~mm}$., being 72.5 per cent. of the normal, while the sacral length is 77.4 per cent. of the normal. Unfortunately the bodies of the vetebræ are imperfectly preserved, but they appear to be rather smaller relatively than is the case in the sacral vertebræ. Thus in progeria the reduction in growth-as regards length-does not affect all parts equally. Those connected with the thorax are chiefly affected and those of the upper limb more than those of the lower limb. It is also seen that cartilage-formed bones suffer to about the same extent as the membrane-formed bones. In this respect progeria differs from achondroplasia.

Pyoportion of limbs to stature. - In life the boy's stature was $1130 \mathrm{~mm}$. ( $3 \mathrm{ft} .8 \frac{1}{2}$ in.). The mid-point of his stature was situated slightly above the symphysis pubis. The total height of the head from occipital condyles to cranial vault

\section{FIG. 9.}

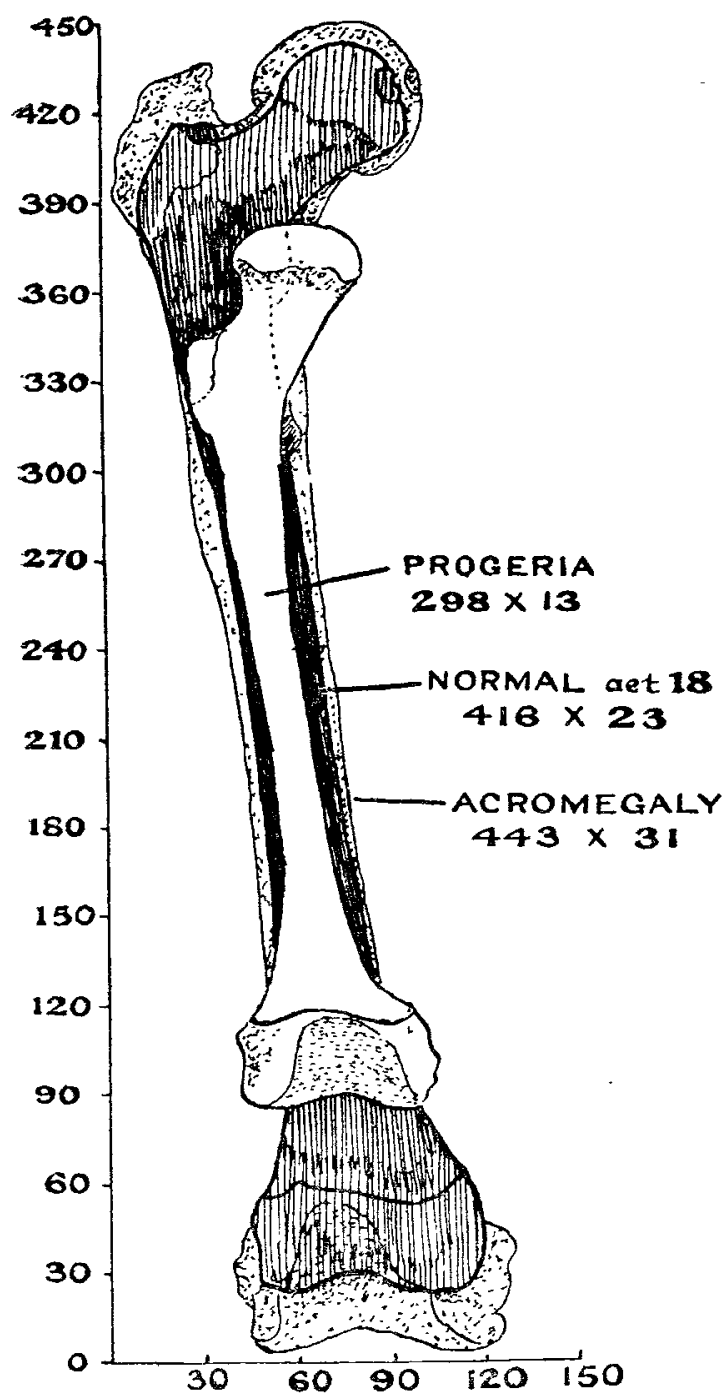

Three femora-progerian, normal, and acromegalic-superimposed to show the differences in their forms. In every respect the progerian ant acromegalic bones are contrasted in form. The scale is shown by the side of the drawing in
millimetres.

was $130 \mathrm{~mm}$; the length of the spine-if it terminated opposite the symphysis-may therefore be estimated at $440 \mathrm{~mm}$. - a sufficient measurement for a boy of his stature. The femur represents 26.3 per cent., tibia 20.3 per cent., humerus $15 \cdot 7$ per cent., and radius 11.8 per cent. of the stature. The humerus especially, and also the radius, fall distinctly short of the normal (20 per cent. for humerus and 14 per cent. for radius), while the proportions of femur and tibia approach closely to the relative proportion found in lads of normal stature. The length of the hands and feet appears also to have been in due proportion to the stature.

Epiphyseal lines. - The condition of the epiphyseal lines, with certain exceptions to be mentioned, was such as is often seen in normal youths of 18 . The condition of the sutural lines of the skull has already been described. Some of these were prematurely closed. Taking the main limb bones first, it is seen that the epiphyses at the elbow-joint, with the exception of the external epicondylar, have united with the shafts of the arm bones; the epiphyseal line at the upper end of the radius is just apparent; the scale-like epiphysis of the olecranon is fused and all traces of the lower epiphyseal line of the humerus gone, with the exception of

FIG. 10.

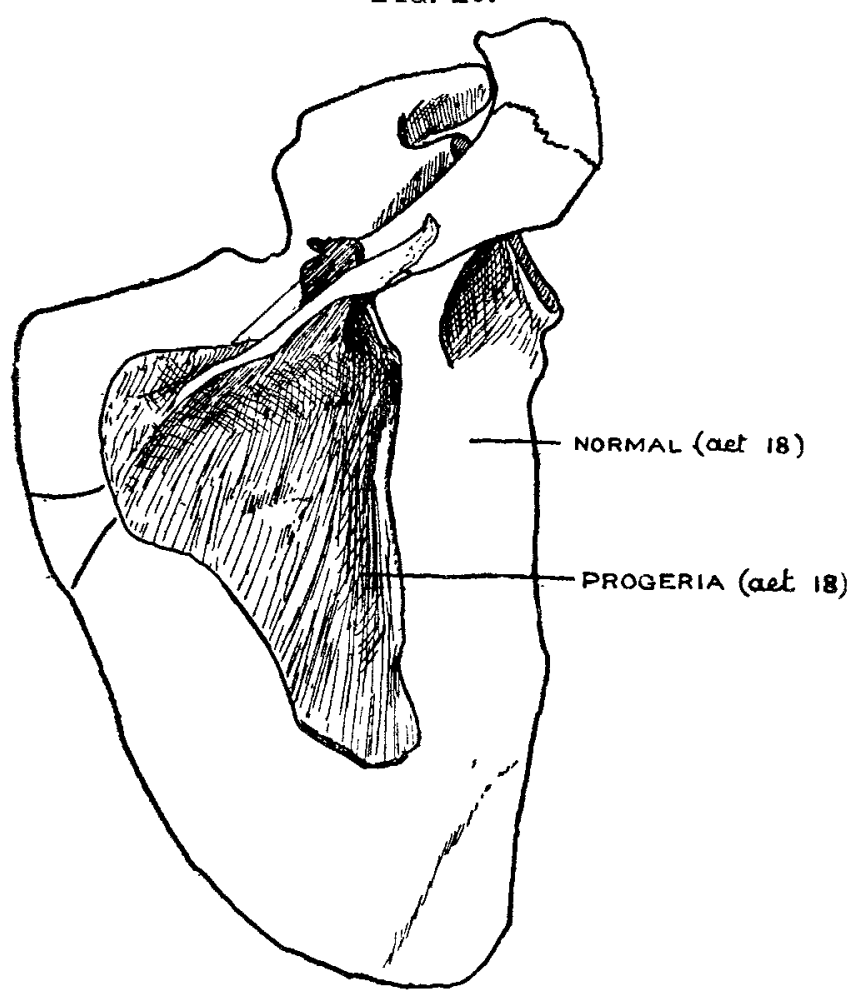

The scapula from the case of progeria superimposed on scapula of a normal lad, aged 18 years (half the natural size).

the external epicondylar, which is still open. The upper humeral and lower radial and ulnar epiphyses are still ununited. The epiphyses at the upper extremity of the femur have joined; those of the femur and tibia on either side of the knee-joint are still unjoined; so are the lower epiphyses of the tibia and both upper and lower epiphyses of the fibula. As regards the state of

FIG. 11.

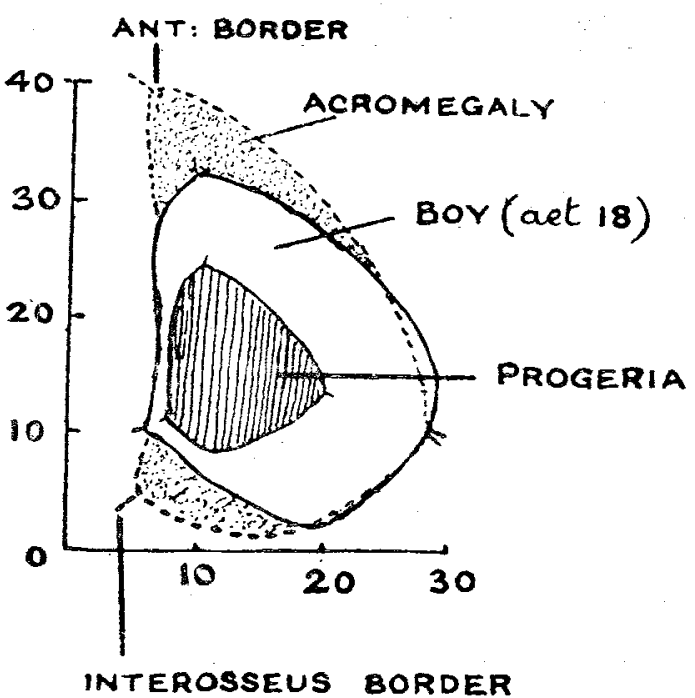

Transverse section at mid-point of the tibia from the case of progeria (shaded). Corresponding sections of the tibia from a boy of 18 and from a case of acromegaly are superimposed (natural size).

union of the epiphyseal lines of the long bones it is such as we expect to find in a normal lad of 18 ; there is neither premature closure nor delay of union. The condition of ossification of the bones of the hands and feet is in advance of 18; the epiphyses of the metatarsal and metacarpal bones have joined, an uncommon condition at the age of 18. The heel epiphysis 
of the os calcis is side a slight trace is to be seen of the line of union between ilinm and ischium; it is probable that the os pubis was not united -not completely united --with the ilium and ischium at the cotyloid cavity. The pubis, unfortunately, is missing from both sides. The epiphysis on the ischial tuberosity is partly united; that of the iliac crest is unjoined. As regards the sacrum there is a delay in the union of parts. The bodies of the sacral vertebræ are ununited ; the lateral masses of the first and second are still unjoined; the sutural lines between the lateral masses of the third and fourth, fourth and fifth sacral vertebræ are still unclosed. The various parts of each vertebre are united. The segments of the mesosternum were observed to be united when the postmortem ezamination was made.

Peoutiar features of the skeletal bones.Although the bones are characteristic in shape, there is not that degree of deformity to be seen in achondroplasia. The appearances are those of a peculiar form of defective ossification. The atlas in its dimensions (extreme width $62 \mathrm{~mm}$., anteroposterior diameter $28 \mathrm{~mm}$.) is normal in size, but of delicate formation; there is a deficiency of the posterior arch, the neural laminx being unfused, a condition to be interpreted in conjunction with the unfilled state of the foramen magnum. The neural arches of the cervical vertebræ are also peculiarly slender; the lamina of the sacral vertebræ are normal in form, those of the fourth and fifth vertebræ are ununited. The slender form of the ribs may be best indicated by comparing transverse sections of the / scapula and its dimensions can be seen from Fig. 10; seventh ribs near their mid-point; in progeria the it cannot be said to be infantile in form, except measurements are $5.5 \times 3 \mathrm{~mm}$., in the ribs of the as regards the spine and acromion, and even they normal boy $13 \times 6 \mathrm{~mm}$. The peculiar characters of the are peculiar. The characteristics of the long bones

FIG. 13.

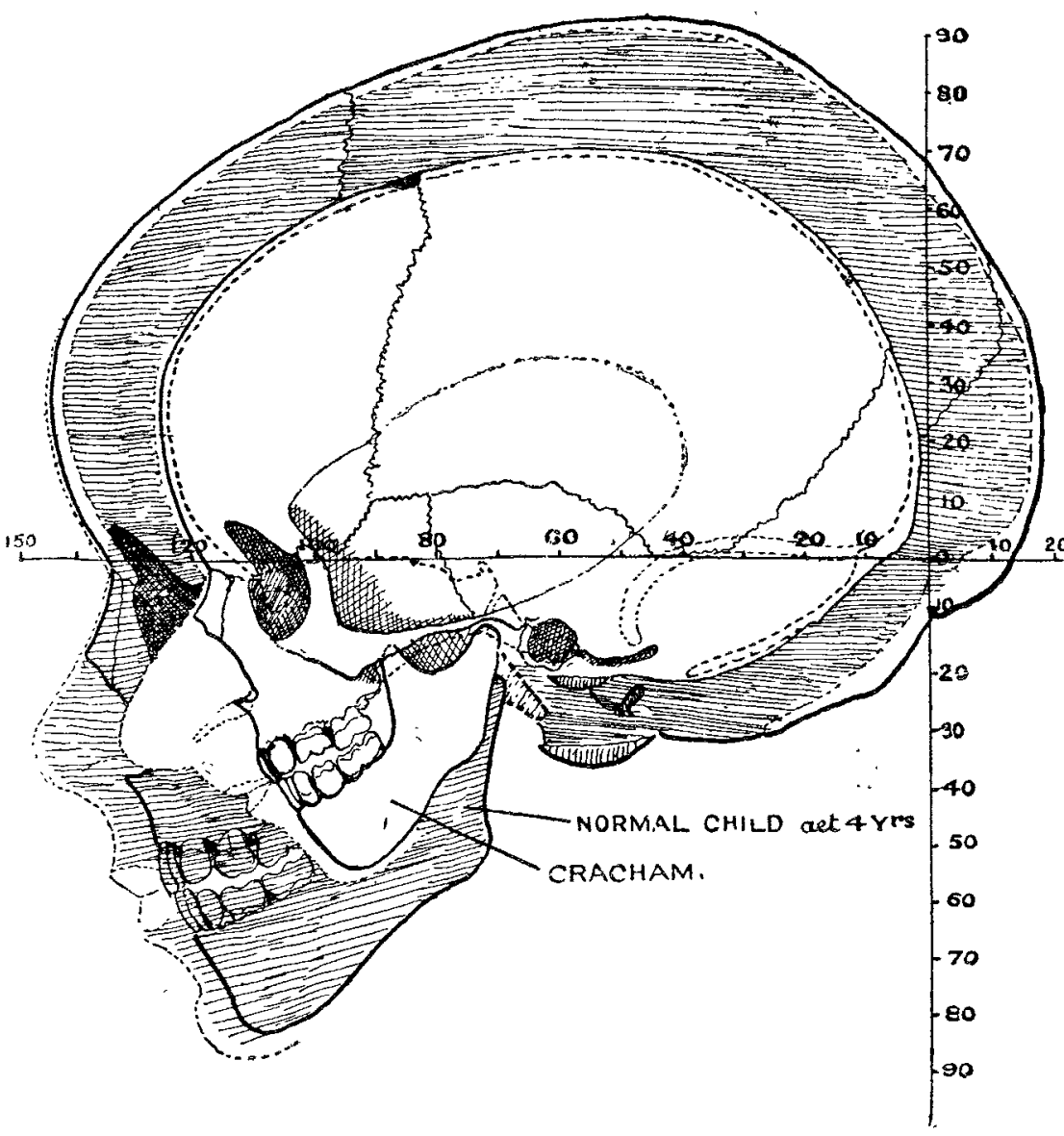

Profile of the skull and face of the dwarf Crachami contrasted with the skull and face of a normal child of four years. The scale of measurements ancl plane of orientation are given. (Reduced half natural size.) are best seen in the femur. In Fig. 9 the progerian and acromegalic femora are contrasted with the femur of a normal boy of 18 . In progeria the deficiency of ossification mainly affects the shaft; the extremities, somewhat peculiar in shape, are less reduced. In the middle of the shaft the back to front diameter is $18 \mathrm{~mm}$, the linea aspera being scarcely raised above the level of the shaft; the side to side diameter $13 \mathrm{~mm}$.; in the normal femur the corresponding measurements are $26 \times 23$, in an acromegalic femur $35 \times 31$. The same measurements at the junction of the upper with the middle third of the shaft are $14 \times 20 \mathrm{~mm}$. (progerian); $27 \times 33$ (normal); $35 \times 38$ (acromegalic). There is a front to back flattening of the upper third of the femoral shaft in progeria. The thickness and uprightness of the neck will be observed in Fig. 9, the angle of the neck with the shaft being $145^{\circ}$; in the normal, $129^{\circ}$; in acromegaly, $125^{\circ}$. The articular surface of the head (diameter $36.5 \mathrm{~mm}$.) is directed upwards and fits within a shallow cotyloid cavity with a diameter of $41 \mathrm{~mm}$. at the brim. In the normal boy the head of the femur has a diameter of $52 \mathrm{~mm}$.; in acromegaly, $55 \mathrm{~mm}$. All muscular ridges and crests are absent from the shafts of the long bones in progeria; muscular insertions are marked by pits or depression. In the humerus the pectoral ridge is a trough-like impression; there is no deltoid eminence; in the radius the bicipital tuberosity is marked by a rough pit. In acromegaly all muscular ridges and ligamentous areas of insertion are raised and hypertrophied. The shaft of the humerus, and especially those of the radius and vlna, are peculiarly slender. The shaft of the humerus, at the insertion of the deltoid, has a sicle to side diameter of $9 \mathrm{~mm}$. a back to front diameter of $9.5 \mathrm{~mm}$.

$$
\mathrm{E} 2
$$


The external cuneiform in the foot is partially fused with the cuboid. As already mentioned, the metatarsal bones are short and slender. The metatarsal of the great toe is especially curtailed. In acromegaly the metatarsal of the great toe is peculiarly liable to hypertrophy.

Fig. 11 will help to convey an accurate conception of the slenderness of the shafts of all the long bones in progeria. Superimposed sections of the tibiæ made at the middle of the shaft are shown from the same three cases as before. The tibia from the "case of progeria is, in its transverse section, about the size of the medullary cavity of the tibia of a normal lad of 18 ; in acromegaly the area is much larger, the shin or anterior crest being greatly developed.

Progeria contrasted with aoromegaly.-In that excellent work, "Disorders of Post-Natal Development," Mr. Hastings Gilford gives a very complete analysis of the nature of progeria, and specially observes that in all its features it forms a contrast with acromegaly. Nevertheless, he regards both progeria and acromegaly, not as negative and positive phases of a single disease, but as contrasted forms of senilism. In progeria, if $\mathbf{I}$ understand $\mathbf{M r}$. Gilford aright, the tissues pass prematurely into the condition which we see in aged men and women; in acromegaly the tissues undergo an atavistic change and assume characters belonging to a long past phase in the evolution of man's body. In acromegaly the tissues are recapitulating ancestral phases -ancestral senilism. It is possible that Mr. Gilford may be right, but my object in describing and investigating progeria and acromegaly is to see if they throw any light on the process or processes which regulate the growth and nutrition of the various tissues of the body. The direct influence of the internal secretions of the genital glands in modifying and determining the growth of the body is admitted. The thyroid, suprarenal, and pituitary glands also yield secretions which influence growth, although we may not yet know the manner nor the extent of their action. The association between acromegaly and adenoma of the pituitary can only be explained at present by supposing that the adenomatous pituitary, by means of a secretion which circulates in the tissues, has produced the series of growth changes seen in acromegaly. ${ }^{6}$

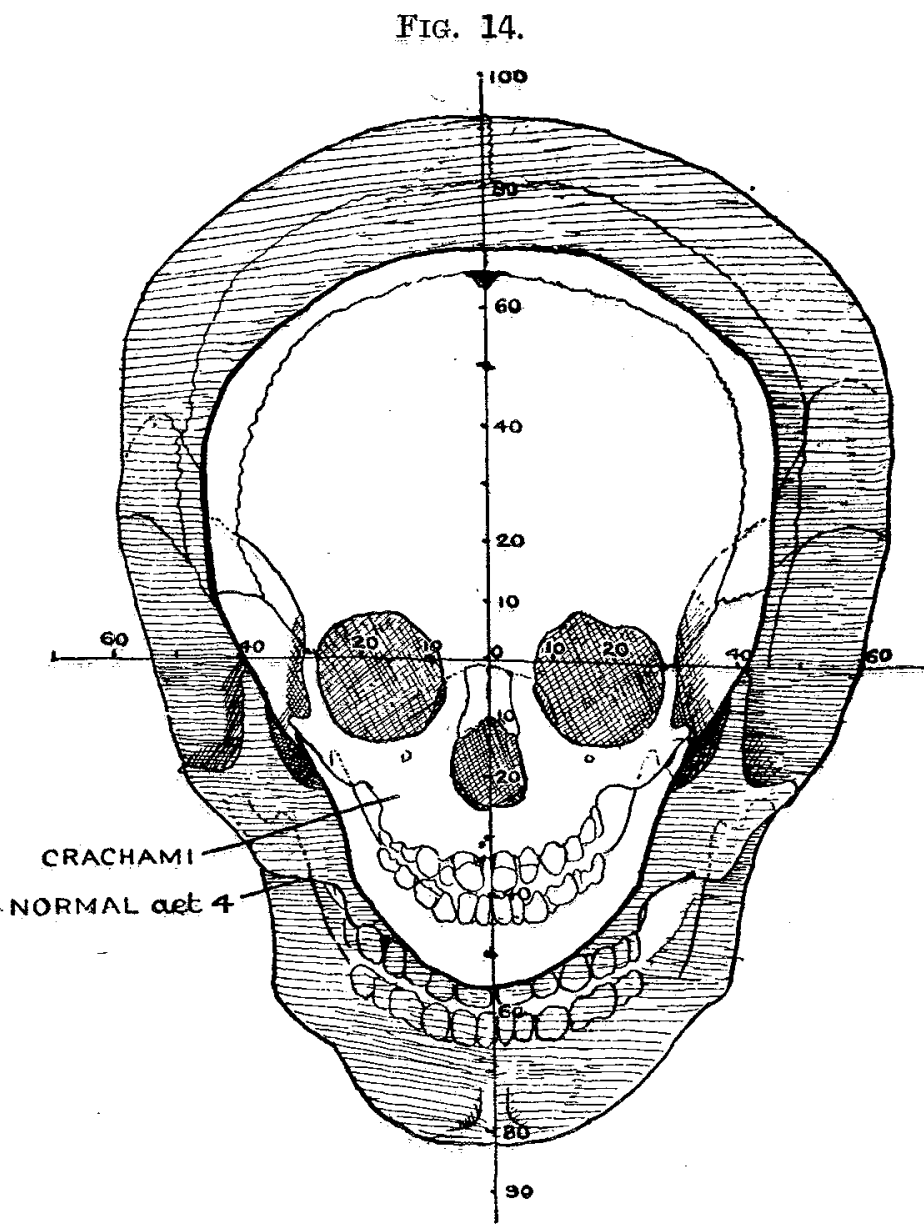

Full-face drawing of Crachami's skull contrasted with that of a child of 4 years. The plane of orientation is the same as natural size). the infant assumes the form, size, and position of the ramus of the adult. In acromegaly the process of growth is reawakened and the ascending ramus assumes the form and size shown in Fig. 12. In progeria there is not merely an arrest of growth, otherwise the ascending ramus would be similar to that of a newly born child. (See Fig. 12.) There has been a slight degree of growth, but from the shape of the mandible one infers that the regulated changes which carry the ramus backward and make room for the eruption of the permanent tooth failed to take place. The second permanent molars are erupting from the inner side of the coronoid processes. The body of the mandible grows normally by formation of new bone along its upper, lower, and anterior border; in acromegaly growth proceeds at these borders. In progeria growth proceeds by a uniform deposition of bone all over the mandible, but is least where it is greatest in acromegaly, along the posterior and upper borders of the mandible.

If we admit that the changes in acromegaly are produced by a stimulus or hormone proceeding from the pituitary, then it must be admitted that the condition in progeria can be best explained by an absence or marked diminution of that stimulus. The positive evidence in favour of such a view is wanting. In the present case the pituitary fossa is smaller than normal, and yet the reduction in size is not sufficient to justify us in affirming that insufficient glandular tissue was present. In achondroplasia the pituitary fossa is small. Dr. Rennie? reports the case of a boy of 16 with an endothelioma of the pituitary; some of the symptoms of that case, where we may suppose the pituitary tissue was invaded and re duced, recall those of progeria. Mr. Jameson Evans ${ }^{8}$ has recorded the case of a dwarf with enlarged pituitary fossa and a case of infantilism with a small pituitary fossa. Tumours of the pituitary are attended by most various results, but the variety of symptoms becomes more easily understood in the light of the researches of $\mathrm{Mr}$. Harvey Cushing. ${ }^{9}$

Fatal ateleiosis oontrasted with progema.-Amongst other services rendered to medicine by Mr. Gilford was the recognition of a very distinct group of cases which he classified under the name of " foetal That is the only working hypothesis we have at present to explain the pathological changes in the pituitary and the growth changes in the tissues of the body.

We have seen that those parts of the skeleton which are overgrown in acromegaly are undergrown in progeria. Acromegaly is not a general overgrowth of all the tissues and systems of the body; its cause is selective in action. Progeria is not a generalised dwarfism; the cause is also selective in its action, and affects those tissues and parts which are also affected in acromegaly. Figs. 5, 9, and 11 illustrate the truth of the statement; it is further exemplified in Fig. 12. In that figure the exact profiles of four mandibles are superimposed and accurately drawn to scale. The mandible at birth is superimposed on the mandible of a normal adult. By addition of new bone along the upper and posterior borders of the ascending ramus and absorption along its anterior border the ramus of

6 For an account of skeletal rhanges in acromegaly see Keith, The LANCET, April 15th, 1911 , Caroline Crachami, whose skeleton is preserved in the Museum of the Royal College of Surgeons. Crachami was nine years of age when she died, but had only the stature of a child at birth (505 mm.) and the condition of the centres of ossification of her skeleton and the size of her long bones are similar to those of a child at 15 months: I allude to her case here in order to publish two figures of her skull, hitherto undescribed, superimposed on the skull of a child of four years. In shape and in some of its features the skull resembles the skull in progeria, but there is one marked difference: its capacity is small ( 600 c.c.) and holds a due proportion to the size of the body. Her brain and teeth, as well as the body, are in miniature. Mr. Gilford regards the condition of foetal

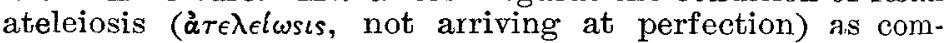
mencing before birth ; the delay or arrest of growth begins ateleiosis." The type case of this condition is represented by 
in utero, and such children are dwarfs at birth. In Orachami the nose is large; it is the only part which is out of proportion. The skull of Crachami differs from that seen in progeria by all the parts being equally arrested in growth ; when Figs. 13 and 14 are examined it will be seen that in the proportions of the skull and face Crachami is a fairly accurate miniature of the head of a normal child. It is possible that ateleiosis stands in the same relationship to progeria as giantism stands to acromegaly. In giantism, as in ateleiosis, the whole body is affected. In progeria and acromegaly the action is selective; certain parts and certain systems are affected more than others. In the case of Crachami no accurate measurement can be made of the pituitary fossa owing to the unossified condition of the dorsum sellæ.

In discussing the pathology of progeria mention ought to have been made of the opinion held by $M$. Variot and $M$. Pironnean that the primary cause of the condition was to be sought in a disorder of the suprarenal bodies. In Mr. Gilford's case there was great reduction in size and cirrhosis of the kidneys with marked atheroma of the coronary arteries of the heart. How far these conditions are a cause or a consequence of the disease remains to be ascertained.

Lincoln's Inn Fields, W.C.

\section{NEW GROWTH AND INEFFICIENT IMMUNITY.}

\section{BY HELEN G. GRÜNBAUM, M.D. BiRM.,} AND

ALBERT S. F. GRÜNBAUM, M.D. CaNtab.

(From the Pathological Department of the University of Leeds.)

IT is now a well-known phenomenon that upon the injection of a vaccine into an animal there ensues a preliminary drop in the opsonic index, followed by a rise above the normal, with a subsequent gradual fall again to the normal line. The period during which the index is below normal-that is, until the manifestation of the immune opsonin-varies with the type and dose of vaccine, but ocoupies generally about 8-10 days. This period is termed the negative phase.

\section{Hemolysophitic Substance and New Growth.}

We have been able to show that after the injection of streptococcus vaccine into the rat, during a period roughly corresponding to the negative phase there is present in the rat's serum a substance which accelerates cobra venom hæmolysis, and later on disappears. That is, if the blood of the rat be tested before inoculation towards cobra venom according to a definite technique, ${ }^{1}$ and found normal, and the rat be then injected with streptococcus vaccine, within 24 hours the serum becomes hæmolytic when tested together with cobra venom. Later on this hæmolytic phase passes off and the antibody (immune body) to the streptococcus appears.

We find that a similar hæmolysophilic property of the serum is present in rats successfully inoculated with a transplantable sarcoma (Ehrlich), but in this case there is apparently no production of immune body to the new growth or to cobra venom, so long as the tumour is growing. Such rats, as we have shown, are especially sensitive to the toxin of cobra venom, but if in response to the injection of cobra venom toxin an antihæmolysin does appear in the blood, the tumour regresses. A similar regression follows the artificial administration of the immune body to cobra venom contained in antivenom serum. We have, then, the following conditions in sarcomatous rats :-

1. A persistent hæmolytic property of the serum.

2. An absence of, and usually an inability to produce, antitoxin to cobra venom; if its production can be excited, the tumour regresses.

3. The administration of antitoxin in the form of antivenom serum causes regression of the tumours.

It seems, therefore, reasonable to infer that the absence of some immune body and the presence of a hrmolytic

1 Journal of Pathology and Bacteriology, vol. xvil.. p. 82. substance in the serum are factors which exert an influence on the growth of the tumour.

Effects of Vacoines and Toxins in Animals and Man.

Injection of vaccines in man also leads to the appearance of a hæmolysophilic property in the blood, but as we have not met with a case of human spindle-cell sarcoma during the period of this investigation, we are not able to say whether the hæmolytic substance is present also in this condition. But there are indications of the existence of a lack of resistance similar to that in rat sarcoma in some other forms of malignant growth. The varying action of Coley's fluid in cases of sarcoma illustrates such a state. As we know, a limited number of cases will react to Coley's fluid (just as a small number of rats will successfully react to cobra venom if given when the growth is small), and presumably in them antibody formation is still possible and is sometimes complete. Such cases should improve under treatment. (We have one human case belonging to this category, but treated with cobra venom. After removal of a periosteal sarcoma of the fernur, the patient's blood still possessed the positive hæmolysing property. It disappeared after the comsined administration of antivenom serum and cobra venom, and has been kept in abeyance by the administration of cobra venom only during the past 16 months.) In another limited number an ephemeral reaction occurs with some amelioration of symptoms, but finally the cases relapse. In yet other cases no reaction to the toxin takes place at all ; the patients appear to have lost the power of protective reaction to these toxins.

This latter condition was well shown by two cases which we had under our care for some months. The one, a case of round-cell sarcoma, steadily improved during the adminis. tration of artificial immune substance in the form of antivenom serum (Pasteur Institute, Lille), but never showed any response by antibody production to cobra venom toxin. The body weight steadily increased (nearly 2 lb. in each of the three weeks that the serum was administered) and the tumour mass decreased markedly in size. The other, a case of carcinoma of the larynx, likewise showed no reaction to injected toxin, but put on $14 \mathrm{lb}$. in weight, and improved steadily so long as the artificial immune body (in this case diphtheria antitoxin) was administered (eight weeks). Unfortunately, at present there are technical difficulties in the way of long-continued administration of immune serum which we hope may be obviated by further investigation.

Most forms of human carcinoma do not as a rule exhibit the persistent hæmolytic reaction associated with the spindlecell sarcoma of rats, but some cases give a similar reaction with viper venom instead of cobra venom. From what has already been said, this was to be expected. There are many forms of immune body and only a few of the laws governing their production are known. The extent of variety in type exhibited by new growths makes it difficult to believe in a uniform cause, but the cases quoted above give support for belief that the same principles may underlie the genesis of all the forms.

\section{Suggestions for Researoh.}

In the meantime, the indications are to attempt still further to correlate the different types of tumours with the substance in the serum which permits or aids their growth. But while the problem may thus be attacked from the chemico-pathological side, there is another method which may well give more rapid results-that is, empirical treat. ment on the lines of supplying various immune substances in the various cases and carefully noting any result which may follow.

For either method the serum of the patient requires examination, and it is best to abstract at least 10 c.c. of blood for the double purpose of having sufficient serum for examination and of attempting to induce the production of immune body. It is well known that bleeding does so, and it may be that our ancestors unconsciously but wisely in this manner replenished, each spring, their stook of antibodies. We have ourselves found that by bleeding rats the hæmolysing property associated with susceptibility to inoculation is markedly diminished.

Hypothesis ooncerning Dual Causation of New Growth.

So far as our experiments go they lend support to d hypothesis put forward by one of us some years ago that more than one factor is concerned in the causation of new 